\title{
Effect of transfusion of fresh frozen plasma on parameters of endothelial condition and inflammatory status in non-bleeding critically ill patients: a prospective substudy of a randomized trial
}

Marleen Straat ${ }^{1,2^{*}}$, Marcella CA Müller ${ }^{1,2}$, Joost CM Meijers ${ }^{3}$, Mendi S Arbous ${ }^{4}$, Angelique ME Spoelstra - de Man ${ }^{5}$, Charlotte JP Beurskens ${ }^{2}$, Margreeth B Vroom ${ }^{1}$ and Nicole P Juffermans ${ }^{1,2}$

\begin{abstract}
Introduction: Much controversy exists on the effect of a fresh frozen plasma (FFP) transfusion on systemic inflammation and endothelial damage. Adverse effects of FFP have been well described, including acute lung injury. However, it is also suggested that a higher amount of FFP decreases mortality in trauma patients requiring a massive transfusion. Furthermore, FFP has an endothelial stabilizing effect in experimental models. We investigated the effect of fresh frozen plasma transfusion on systemic inflammation and endothelial condition.

Methods: A prospective predefined substudy of a randomized trial in coagulopathic non-bleeding critically ill patients receiving a prophylactic transfusion of FFP $(12 \mathrm{ml} / \mathrm{kg})$ prior to an invasive procedure. Levels of inflammatory cytokines and markers of endothelial condition were measured in paired samples of 33 patients before and after transfusion. The statistical tests used were paired $t$ test or the Wilcoxon signed-rank test.

Results: At baseline, systemic cytokine levels were mildly elevated in critically ill patients. FFP transfusion resulted in a decrease of levels of TNF-a (from 11.3 to $2.3 \mathrm{pg} / \mathrm{ml}, P=0.01$ ). Other cytokines were not affected. FFP also resulted in a decrease in systemic syndecan-1 levels (from 675 to $565 \mathrm{pg} / \mathrm{ml}, P=0.01$ ) and a decrease in factor VIII levels (from 246 to $246 \%, P<0.01$ ), suggestive of an improved endothelial condition. This was associated with an increase in ADAMTS13 levels (from 24 to 32\%, $P<0.01$ ) and a concomitant decrease in von Willebrand factor (vWF) levels (from 474 to $423 \%, P<0.01$ ).
\end{abstract}

Conclusions: A fixed dose of FFP transfusion in critically ill patients decreases syndecan-1 and factor VIII levels, suggesting a stabilized endothelial condition, possibly by increasing ADAMTS13, which is capable of cleaving vWF.

Trial registrations: Trialregister.nl NTR2262, registered 26 March 2010 and Clinicaltrials.gov NCT01143909, registered 14 June 2010.

\footnotetext{
* Correspondence: m.straat@amc.uva.nl

${ }^{1}$ Department of Intensive Care Medicine, Academic Medical Center,

Meibergdreef 9, Amsterdam 1105 AZ, The Netherlands

${ }^{2}$ Laboratory of Experimental Intensive Care and Anesthesiology, Academic

Medical Center, Meibergdreef 9, Amsterdam 1105 AZ, The Netherlands

Full list of author information is available at the end of the article
} 


\section{Introduction}

Substantial units of fresh frozen plasma (FFP) are utilized in the intensive care unit (ICU) [1,2]. FFP is effective in correcting clotting factor deficiencies [3] and is therefore transfused in patients with active bleeding, but also frequently in patients with abnormal coagulation tests to prevent bleeding $[2,4]$. In sepsis patients, FFP transfusion rates of up to $57 \%$ have been reported [5]. However, there is an association between FFP transfusion and adverse outcome in the critically ill, including transfusion-related acute lung injury (TRALI) [4,6-8], transfusion-related circulatory overload $[9,10]$, multiorgan failure $[8,11]$ and an increased risk of infections [12]. Although not entirely understood, the pathological mechanisms underlying the association between FFP transfusion and lung injury is thought to result from an inflammatory response including a neutrophil influx into the lungs and elevated pulmonary levels of interleukin 8 (IL-8) and interleukin 1 (IL-1), as demonstrated in TRALI patients $[13,14]$. In line with this, FFP increased expression of endothelial adhesion molecules in human pulmonary endothelial cells [15]. Together, these data suggest that endothelial cell activation and disruption may be an early event following lung injury due to transfusion [16].

On the other hand, FFP also seems to have protective effects. In trauma patients requiring a massive transfusion, resuscitation with a higher ratio of FFP to red blood cell units is associated with decreased mortality $[17,18]$. Interestingly, some studies suggest that this decreased mortality is irrespective of correction of coagulopathy by restoring coagulation factor levels $[18,19]$, although not all studies support this observation [20,21]. Instead, a beneficial effect of FFP may be related to the restoration of injured endothelium. Syndecan-1 is a proteoglycan on the luminal surface of endothelial cells that inhibits leukocyte adhesion. During endothelial damage, syndecan-1 is shed, resulting in increased levels of syndecan-1 in the systemic compartment [22]. Patients in hemorrhagic shock have a disrupted endothelial integrity and glycocalyx layer, with decreased syndecan-1 expression [23]. Vascular integrity is also disrupted in various populations of critically ill patients, as demonstrated by increased systemic levels of syndecan-1 $[24,25]$. Of interest, in a hemorrhagic shock model, FFP was found to improve endothelial integrity, associated with increased expression of syndecan-1 on endothelial cells [26].

The effect of transfusion of FFP on endothelial and cytokine host response in patients is unknown. In a study investigating the risk-benefit ratio of FFP transfusion in non-bleeding critically ill patients with a coagulopathy, we investigated the inflammatory and endothelial host response to a fixed dose of FFP transfusion.

\section{Methods}

\section{Study design}

This was a predefined post hoc substudy of a multicenter trial in which non-bleeding critically ill patients with an increased international normalized ratio (INR, 1.5 to 3.0) were randomized between May 2010 and June 2013 to omitting or administering a prophylactic transfusion of FFP $(12 \mathrm{ml} / \mathrm{kg})$ prior to an invasive procedure. Only patients randomized to receive FFP were included in this substudy. Patients were enrolled at three sites in The Netherlands: two university hospitals (Academic Medical Center, Amsterdam and Leiden University Medical Center, Leiden) and one large teaching hospital (Tergooi Ziekenhuizen, Hilversum). The Institutional Review Board of the Academic Medical Center approved the study protocol. Before entry in the study, written informed consent was obtained from the patient or legal representative in accordance with the Declaration of Helsinki. The study protocol was registered with trial identification numbers NTR2262 and NCT01143909 [27].

Exclusion criteria were clinically overt bleeding, thrombocytopenia of $<30 \times 10^{9} / \mathrm{L}$, treatment with vitamin $\mathrm{K}$ antagonists, activated protein $\mathrm{C}$, abciximab, tirofiban, ticlopidine or prothrombin complex concentrates and a history of congenital or acquired coagulation factor deficiency or bleeding diathesis. Patients treated with low-molecular-weight heparin (LMWH) or heparin in therapeutic dose were eligible if medication was discontinued for an appropriate period. Sepsis was defined by the Bone criteria [28]. Disseminated intravascular coagulation (DIC) was defined by an International Society on Thrombosis and Haemostasis (ISTH) score of $\geq 5$ [29]. The FFP was quarantine plasma manufactured by Sanquin, the Dutch National Blood Bank. As of 2007, women are deferred for donation for preparation of FFP in the Netherlands.

\section{Sample collection}

Citrated blood samples were drawn from an indwelling arterial catheter before and within 10 minutes after FFP transfusion. During transfusion, respiratory settings were kept constant. Samples were collected in sodium citrate $(0.109 \mathrm{M} \mathrm{3.2 \%})$ tubes and were centrifuged twice within 30 minutes: the first 15 minutes at 2,000 $\times g$ and then 5 minutes at $15,000 \times g$, both at $18^{\circ} \mathrm{C}$. Supernatant was collected and stored at $-80^{\circ} \mathrm{C}$.

\section{Assays}

Tumor necrosis factor alpha (TNF- $\alpha$ ) levels were measured by enzyme-linked immunosorbent assay (ELISA), according to instructions of the manufacturer (R\&D Systems Inc., Minneapolis, MN, USA). Serum levels of interleukin 1 beta (IL-1 $\beta$ ), interleukin 1 receptor antagonist (IL-1RA), IL-8, interleukin 10 (IL-10), macrophage 
inflammatory proteins (MIP)-1A, monocyte chemotactic protein (MCP)-1 and soluble CD40 ligand (sCD40L) were determined by Luminex, according to the manufacturer's instructions (Merck Millipore Chemicals BV, Amsterdam, The Netherlands). When less than 50 beads were measured by the Luminex assay, samples were excluded from further analysis. von Willebrand factor antigen (vWF:Ag) levels were determined with an in-house ELISA using commercially available polyclonal antibodies against von Willebrand factor (vWF) (Dako, Glostrup, Denmark). ADAMTS13 (a disintegrin and metalloproteinase with a thrombospondin type 1 motif, member 13) activity was determined as described earlier [30]. Factor VIII activity was determined on a Behring XP coagulation analyzer using reagents and protocols from the manufacturer (Siemens Healthcare Diagnostics, Marburg, Germany).

\section{Statistical analysis}

Variables are expressed as medians and interquartile ranges (IQRs) or means and standard deviations (SDs). For comparisons, a paired $t$ test was used, or the Wilcoxon signed-rank test in case of not normally distributed data. For the analyses, we used SPSS version 21.0 (IBM Corp., Armonk, NY, USA) and Graphpad Prism 5 (Graphpad Software Inc., San Diego, CA, USA).

\section{Results}

\section{Patients}

From 38 patients receiving FFP, paired samples from 33 patients were available for analysis before and after FFP transfusion. Patients were ill, as reflected by a high disease severity score and half of the patients had sepsis (Table 1 ). Patients received a mean dosage of 11.2 (2.8) $\mathrm{ml} / \mathrm{kg}$ FFP, which was transfused in $121 \pm 43$ minutes.

\section{Inflammatory cytokine and chemokine levels before and after transfusion of $12 \mathrm{ml} / \mathrm{kg}$ FFP}

At baseline, levels of cytokines were mildly elevated in this cohort. After FFP transfusion, median TNF- $\alpha$ decreased $(P=0.01$, Table 2$)$. Levels of all other cytokines were not affected by FFP transfusion. Chemokine levels IL- 8 and MCP-1 were elevated at baseline but also not influenced by FFP transfusion. Levels of sCD40L, which has been implicated as a mediator in TRALI [31], were also not significantly altered by FFP transfusion.

\section{Parameters of endothelial condition before and after} transfusion of $12 \mathrm{ml} / \mathrm{kg}$ FFP

After FFP transfusion, levels of ADAMTS13 increased $(P<0.01$, Table 3 and Figure 1$)$. This increase was accompanied by a decrease in vWF $(P<0.001)$ and in systemic levels of syndecan-1 $(P=0.01)$. Factor VIII
Table 1 Patient characteristics

FFP transfusion $\mathrm{N}=33$

\section{General characteristics}

Gender, male, n (\%)

21 (64)

Age (years)

$61(50-70)$

APACHE IV score

$96(79-128)$

SOFA score

$11(10-14)$

\section{Medical history}

Pulmonary disease, $\mathrm{n}(\%) \quad 3$ (9)

Liver disease, $\mathrm{n}(\%) \quad 6$ (18)

Cardiac failure, $\mathrm{n}(\%) \quad 6(18)$

Medical condition 24 hours

before transfusion

Mechanical ventilation, $\mathrm{n}(\%) \quad 27(82)$

Sepsis, n (\%) $15(45)$

Disseminated intravascular coagulation, n (\%) 16 (49)

Clinical outcomes

ICU length of stay

$12(6-23)$

Mortality

21 (64)

Data expressed as median and interquartile ranges. FFP, fresh frozen plasma; APACHE IV score, acute physiology and chronic health evaluation IV score; SOFA score, sequential organ failure assessment score; ICU, intensive care unit.

levels were slightly decreased following FFP transfusion $(P=0.02)$.

\section{Discussion}

Our patients had mildly elevated levels of inflammatory cytokines at baseline, which corresponds to levels measured before in critically ill patients [32]. We observed

Table 2 Inflammatory cytokines in critically ill patients before and after a transfusion of fresh frozen plasma $(12 \mathrm{ml} / \mathrm{kg})$

\begin{tabular}{|c|c|c|c|}
\hline & Before FFP & After FFP & $P$ value \\
\hline \multicolumn{4}{|c|}{ Proinflammatory parameters $(\mathrm{pg} / \mathrm{ml})$} \\
\hline TNF-a & $11.3(2.3-52.3)$ & $2.3(2.3-41.0)$ & 0.01 \\
\hline$I L-1 \beta$ & 15.0 (11.7-18.8) & $14.4(13.1-23.3)$ & 0.97 \\
\hline IL-8 & $178(124-418)$ & $187(113-412)$ & 0.23 \\
\hline MCP-1 & $1255(503-3376)$ & $1101(434-5802)$ & 0.89 \\
\hline MIP-1A & $19.6(15.7-33.6)$ & $19.1(13.3-34.4)$ & 0.12 \\
\hline sCD40L & $409(257-614)$ & $324(216-537)$ & 0.08 \\
\hline \multicolumn{4}{|c|}{ Anti-inflammatory parameters (pg/ml) } \\
\hline IL-1RA & $69.3(52.1-110.6)$ & $73.5(47.8-104.9)$ & 0.11 \\
\hline IL-10 & $36.1(15.5-100.1)$ & 31.5 (14.8-279.6) & 0.62 \\
\hline
\end{tabular}

Data expressed as median (IQR). FFP, fresh frozen plasma; TNF-a, tumor necrosis factor alpha; IL-1 $\beta$, interleukin 1 beta; IL-8, interleukin 8; MCP-1, monocyte chemotactic protein $1 ;$ MIP-1A, macrophage inflammatory proteins $1 \mathrm{~A} ; \mathrm{SCD} 40 \mathrm{~L}$, soluble CD40 ligand; IL-1RA, interleukin 1 receptor antagonist; IL-10, interleukin $10 ; \mathrm{IQR}$, interquartile range. 
Table 3 Parameters of endothelial condition in critically ill patients before and after a transfusion of fresh frozen plasma $(12 \mathrm{ml} / \mathbf{k g})$

\begin{tabular}{llll}
\hline & Before FFP & After FFP & $\boldsymbol{P}$ value \\
\hline VWF-Ag & $474.0(331.5-639.5)$ & $423.0(313.5-539.0)$ & $<0.001$ \\
Factor VIII & $246.4(203.6-364.4)$ & $246.40(321.2)$ & $<0.01$ \\
ADAMTS13 & $23.9(15.8)$ & $31.7(17.9)$ & $<0.001$ \\
Syndecan-1 & $674.6(132.2-1689.8)$ & $565.1(126.8-1175.7)$ & $<0.01$
\end{tabular}

Data expressed as median (IQR) or mean (SD). FFP, fresh frozen plasma; vWF: $\mathrm{Ag}$, von Willebrand factor antigen; ADAMTS13, a disintegrin and metalloproteinase with a thrombospondin type 1 motif, member 13 ; IQR, interquartile range; $\mathrm{SD}$, standard deviation.

no aggravation of this inflammatory response after FFP transfusion. Rather, there was a decrease in TNF- $\alpha$ level. This is not in line with a study in which FFP elicited an inflammatory response in endothelial cells [33], nor with an in vitro model of transfusion, in which whole blood incubated with FFP induced TNF- $\alpha$ production [34].

Of the cytokines we measured, only TNF- $\alpha$ changed after FFP transfusion. As TNF- $\alpha$ is known to be the quickest responder among all cytokines, we may have timed our measurement too early after FFP transfusion to note an effect of FFP on other cytokine levels. However, lung injury following transfusion is thought to be an early event. Also, we choose this early time point to minimize confounding by other factors. Taken together, FFP does not appear to elicit an early inflammatory response.

Of interest, recent in vitro studies support an endothelial stabilizing role of FFP, as FFP reduced vascular endothelial cell permeability $[26,35]$ and decreased expression of endothelial adhesion markers [36] and endothelial white blood cell binding [26,36,37]. Effects of FFP were investigated in a rat hemorrhagic shock model, characterized by systemic shedding of syndecan-1, decreased syndecan-1 expression on pulmonary cells and increased pulmonary vascular permeability. Resuscitation with FFP abrogated these effects, whereas resuscitation with crystalloids did not [26], and was associated with preservation of the endothelial glycocalyx [38] and improvement of lung injury [39].

In trauma patients with hemorrhagic shock, syndecan-1 levels are also increased [23]. Studies of the effect of FFP on endothelial condition in patients are, however, lacking. Of note, recent evidence in trauma patients requiring a massive transfusion suggests that higher dose and earlier administration of FFP decreases mortality [17,18,40,41]. This effect was not associated with improved coagulation ability, as the reduction in mortality in their study was irrespective of the admission INR [18] and coagulopathy does not seem to improve with higher amounts of FFP [19]. Given that FFP restores coagulation factors but also anti-coagulant proteins and that the net effect on hemostasis is unclear, FFP may exert protection via other mechanisms. We found that FFP decreased levels of syndecan-1, associated with decreased levels of factor VIII, which both reflect improved endothelial condition. These results support earlier experimental work indicating that FFP preserves endothelial integrity.

The mechanism underlying this beneficial effect of FFP has not yet been described. We found that FFP transfusion was associated with an increase in ADAMTS13 and a decrease in vWF. Thereby, ADAMTS13 may have increased the ability to cleave large vWF multimers present on the activated endothelium. As large vWF multimers damage the endothelium, this effect may have preserved endothelial condition. This is also the rationale behind the treatment of thrombotic thrombocytopenic purpura by therapeutic plasma exchange.

A protective effect of FFP on the endothelium is in apparent contrast with studies that have linked FFP to the occurrence of TRALI [4,6-8]. In an effort to reconcile these findings, we suggest that FFP associated with TRALI occurs as a result of an antibody-mediated pathogenesis. Indeed, efforts to reduce antibody-positive blood products by male-only policies are associated with a significant reduction in TRALI [42]. In patients in whom transfusion is associated with lung injury in the absence of antibodies, other products such as red blood cells and platelets may be more important in inducing lung injury. Although dissecting these effects in multiple transfused patients is a challenge, future research should focus on the differential effects of the various blood products.

This study is limited by a small and heterogeneous patient population. Thereby, some of the effects may be caused by chance or by regression to the mean. Findings need to be confirmed in a larger sample. The strengths of this study are the use of a fixed dose of FFP and the timing of blood draws both prior and after transfusion, limiting a possible effect of confounders on findings. Thereby, long-term effects of FFP were not investigated in this design.

\section{Conclusions}

In conclusion, this study is the first to describe the effect of a fixed dose of FFP transfusion in critically ill patients. Results suggest that FFP stabilizes endothelial condition.

\section{Key messages}

- Transfusion of fresh frozen plasma in critically ill patients did not aggravate their inflammatory response.

- In critically ill patients, fresh frozen plasma may stabilize endothelial condition. 


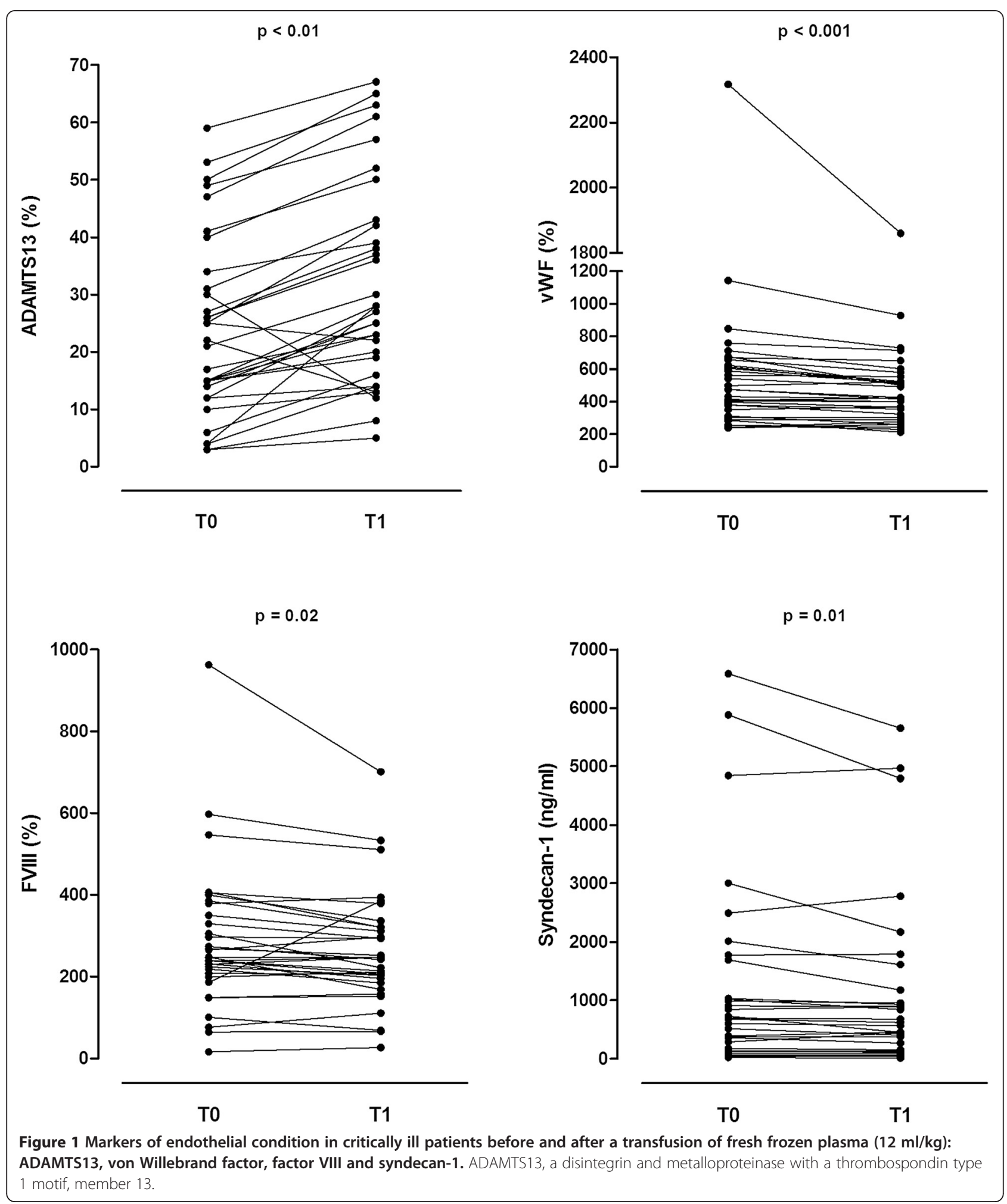




\section{Abbreviations}

ADAMTS13: a disintegrin and metalloproteinase with a thrombospondin type 1 motif, member 13; APACHE IV score: acute physiology and chronic health evaluation IV score; DIC: disseminated intravascular coagulation; ELISA: enzyme-linked immunosorbent assay; FFP: fresh frozen plasma; ICU: intensive care unit; IL-1: interleukin 1; IL-10: interleukin 10; IL-1RA: interleukin 1 receptor antagonist; IL-13: interleukin 1 beta; IL-8: interleukin 8; INR: international normalized ratio; IQR: interquartile range; ISTH: International Society on Thrombosis and Haemostasis; LMWH: low-molecular-weight heparin; MCP-1: monocyte chemotactic protein 1; MIP-1A: macrophage inflammatory proteins 1A; SCD40L: soluble CD40 ligand; SD: standard deviation; SOFA score: sequential organ failure assessment score; TNF-a: tumor necrosis factor alpha; TRALI: transfusion-related acute lung injury; VWF: von Willebrand factor; vWF:Ag: von Willebrand factor antigen.

\section{Competing interests}

The authors declare that they have no competing interests.

\section{Authors' contributions}

MS designed the study, enrolled the patients, collected patient samples, performed analyses on the patient samples and drafted the manuscript. MCAM designed the study, enrolled the patients, collected patient samples, performed analyses on the patient samples and critically revised and approved the final manuscript. MBV designed the study and critically revised and approved the final manuscript. MSA enrolled the patients, collected patient samples and critically revised and approved the final manuscript. AMESM enrolled the patients, collected patient samples and critically revised and approved the final manuscript. CJPB performed the analyses on the patient samples and critically revised and approved the final manuscript. JCMM performed the analyses on the patient samples and critically revised and approved the final manuscript. NPJ designed the study, performed the analyses on the patient samples and drafted the manuscript and critically revised and approved the final manuscript. All authors read and approved the final manuscript.

\section{Acknowledgements}

The study was funded by ZonMw Netherlands, Organization for Health, Research and Development, The Hague, The Netherlands (Project 171002206).

\section{Author details}

'Department of Intensive Care Medicine, Academic Medical Center, Meibergdreef 9, Amsterdam 1105 AZ, The Netherlands. ${ }^{2}$ Laboratory of Experimental Intensive Care and Anesthesiology, Academic Medical Center, Meibergdreef 9, Amsterdam 1105 AZ, The Netherlands. ${ }^{3}$ Department of Experimental Vascular Medicine, Academic Medical Center, Meibergdreef 9, Amsterdam 1105 AZ, The Netherlands. ${ }^{4}$ Department of Intensive Care Medicine, Leiden University Medical Center, Albinusdreef 2, Leiden 2333 ZA, The Netherlands. ${ }^{5}$ Department of Intensive Care Medicine, VU Medical Center, De Boelelaan 1117, Amsterdam 1081 HZ, The Netherlands.

\section{Received: 6 October 2014 Accepted: 20 February 2015}

\section{Published online: 15 April 2015}

\section{References}

1. Stanworth SJ, Grant-Casey J, Lowe D, Laffan M, New H, Murphy MF, et al. The use of fresh frozen plasma in England: high levels of inappropriate use in adults and children. Transfusion. 2011;51:62-70.

2. Tinmouth A, Thompson T, Arnold DM, Callum JL, Gagliardi K, Lauzon D, et al. Utilization of frozen plasma in Ontario: a provincewide audit reveals a high rate of inappropriate transfusions. Transfusion. 2013;53:2222-9.

3. O'Shaughnessy DF, Atterbury C, Bolton Maggs P, Murphy M, Thomas D, Yates $S$, et al. Guidelines for the use of fresh-frozen plasma, cryoprecipitate and cryosupernatant. Br J Haematol. 2004;126:11-28.

4. Dara SI, Rana R, Afessa B, Moore SB, Gajic O. Fresh frozen plasma transfusion in critically ill medical patients with coagulopathy. Crit Care Med. 2005;33:2667-71.

5. Reiter $\mathrm{N}$, Wesche $\mathrm{N}$, Perner $\mathrm{A}$. The majority of patients in septic shock are transfused with fresh-frozen plasma. Dan Med J. 2013;60:A4606.
6. Vlaar AP, Binnekade JM, Prins D, van Stein D, Hofstra JJ, Schultz MJ, et al. Risk factors and outcome of transfusion-related acute lung injury in the critically ill: a nested case-control study. Crit Care Med. 2010;38:771-8.

7. Gajic O, Rana R, Mendez JL, Rickman OB, Lymp JF, Hubmayr RD, et al. Acute lung injury after blood transfusion in mechanically ventilated patients. Transfusion. 2004;44:1468-74.

8. Watson GA, Sperry JL, Rosengart MR, Minei JP, Harbrecht BG, Moore EE, et al. Fresh frozen plasma is independently associated with a higher risk of multiple organ failure and acute respiratory distress syndrome. J Trauma. 2009;67:221-7.

9. Li G, Rachmale S, Kojicic M, Shahjehan K, Malinchoc M, Kor DJ, et al. Incidence and transfusion risk factors for transfusion-associated circulatory overload among medical intensive care unit patients. Transfusion. 2011;51:338-43.

10. Narick C, Triulzi DJ, Yazer MH. Transfusion-associated circulatory overload after plasma transfusion. Transfusion. 2012;52:160-5.

11. Johnson JL, Moore EE, Kashuk JL, Banerjee A, Cothren CC, Biffl WL, et al. Effect of blood products transfusion on the development of postinjury multiple organ failure. Arch Surg. 2010;145:973-7.

12. Sarani B, Dunkman WJ, Dean L, Sonnad S, Rohrbach Jl, Gracias VH. Transfusion of fresh frozen plasma in critically ill surgical patients is associated with an increased risk of infection. Crit Care Med. 2008:36:1114-8.

13. Toy P, Gajic O, Bacchetti P, Looney MR, Gropper MA, Hubmayr R, et al. Transfusion-related acute lung injury: incidence and risk factors. Blood. 2012;119:1757-67.

14. Vlaar AP, Hofstra JJ, Determann RM, Veelo DP, Paulus F, Levi M, et al. Transfusion-related acute lung injury in cardiac surgery patients is characterized by pulmonary inflammation and coagulopathy: a prospective nested case-control study. Crit Care Med. 2012;40:2813-20.

15. Letourneau PA, Pati S, Gerber MH, Jimenez F, Holcomb JB. Fresh frozen plasma increases adhesion molecule expression on human pulmonary endothelial cells. J Surg Res. 2010;163:317-22.

16. Vlaar AP, Juffermans NP. Transfusion-related acute lung injury: a clinical review. Lancet. 2013;382:984-94.

17. Holcomb JB, Wade CE, Michalek JE, Chisholm GB, Zarzabal LA, Schreiber MA, et al. Increased plasma and platelet to red blood cell ratios improves outcome in 466 massively transfused civilian trauma patients. Ann Surg. 2008;248:447-58

18. Brown LM, Aro SO, Cohen MJ, Holcomb JB, Wade CE, Brasel KJ, et al. A high fresh frozen plasma: packed red blood cell transfusion ratio decreases mortality in all massively transfused trauma patients regardless of admission international normalized ratio. J Trauma. 2011;71:S358-63.

19. Chambers LA, Chow SJ, Shaffer LE. Frequency and characteristics of coagulopathy in trauma patients treated with a low- or high-plasma-content massive transfusion protocol. Am J Clin Pathol. 2011;136:364-70.

20. Doussau A, Perez P, Puntous M, Calderon J, Jeanne M, Germain C, et al. Fresh-frozen plasma transfusion did not reduce 30-day mortality in patients undergoing cardiopulmonary bypass cardiac surgery with excessive bleeding: the PLASMACARD multicenter cohort study. Transfusion. 2014;54:1114-24.

21. Nienaber U, Innerhofer P, Westermann I, Schochl H, Attal R, Breitkopf $R_{t}$ et al. The impact of fresh frozen plasma vs coagulation factor concentrates on morbidity and mortality in trauma-associated haemorrhage and massive transfusion. Injury. 2011;42:697-701.

22. Hayashida K, Parks WC, Park PW. Syndecan-1 shedding facilitates the resolution of neutrophilic inflammation by removing sequestered CXC chemokines. Blood. 2009;114:3033-43.

23. Haywood-Watson RJ, Holcomb JB, Gonzalez EA, Peng Z, Pati S, Park PW et al. Modulation of syndecan-1 shedding after hemorrhagic shock and resuscitation. PLoS One. 2011;6, e23530.

24. Steppan J, Hofer S, Funke B, Brenner T, Henrich M, Martin E, et al. Sepsis and major abdominal surgery lead to flaking of the endothelial glycocalix. I Surg Res. 2011;165:136-41.

25. Ostrowski SR, Berg RM, Windelov NA, Meyer MA, Plovsing RR, Moller K, et al. Coagulopathy, catecholamines, and biomarkers of endothelial damage in experimental human endotoxemia and in patients with severe sepsis: a prospective study. J Crit Care. 2013;28:586-96.

26. Peng Z, Pati S, Potter D, Brown R, Holcomb JB, Grill R, et al. Fresh frozen plasma lessens pulmonary endothelial inflammation and hyperpermeability 
after hemorrhagic shock and is associated with loss of syndecan 1. Shock. 2013;40:195-202.

27. Muller MC, de Jonge E, Arbous MS, Spoelstra-de Man AM, Karakus A, Vroom MB, et al. Transfusion of fresh frozen plasma in non-bleeding ICU patients-TOPIC trial: study protocol for a randomized controlled trial. Trials. 2011;12:266

28. Bone RC, Sibbald WJ, Sprung CL. The ACCP-SCCM consensus conference on sepsis and organ failure. Chest. 1992;101:1481-3.

29. Taylor FB Jr, Toh CH, Hoots WK, Wada H, Levi M. Towards definition, clinica and laboratory criteria, and a scoring system for disseminated intravascular coagulation. Thromb Haemost. 2001;86:1327-30.

30. Kostousov V, Fehr J, Bombeli T. Novel, semi-automated, 60-min-assay to determine von Willebrand factor cleaving activity of ADAMTS-13. Thromb Res. 2006; 118:723-31.

31. Khan SY, Kelher MR, Heal JM, Blumberg N, Boshkov LK, Phipps R, et al. Soluble CD40 ligand accumulates in stored blood components, primes neutrophils through CD40, and is a potential cofactor in the development of transfusion-related acute lung injury. Blood. 2006;108:2455-62.

32. Shorr AF, Thomas SJ, Alkins SA, Fitzpatrick TM, Ling GS. D-dimer correlates with proinflammatory cytokine levels and outcomes in critically ill patients. Chest. 2002;121:1262-8.

33. Urner M, Herrmann IK, Buddeberg F, Schuppli C, Roth Z'graggen B, Hasler $M$, et al. Effects of blood products on inflammatory response in endothelial cells in vitro. PLoS One. 2012;7, e33403.

34. Schneider SO, Rensing H, Graber S, Kreuer S, Kleinschmidt S, Kreimeier S, et al. Impact of platelets and fresh frozen plasma in contrast to red cell. concentrate on unstimulated and stimulated cytokine release in an in vitro model of transfusion. Scand J Immunol. 2009:70:101-5.

35. Pati S, Matijevic N, Doursout MF, Ko T, Cao Y, Deng X, et al. Protective effects of fresh frozen plasma on vascular endothelial permeability, coagulation, and resuscitation after hemorrhagic shock are time dependent and diminish between days 0 and 5 after thaw. J Trauma. 2011;69:S55-63.

36. Nohe B, Kiefer RT, Ploppa A, Haeberle HA, Schroeder TH, Dieterich HJ. The effects of fresh frozen plasma on neutrophil-endothelial interactions. Anesth Analg. 2003;97:216-21.

37. Wataha K, Menge T, Deng X, Shah A, Bode A, Holcomb JB, et al. Spray-dried plasma and fresh frozen plasma modulate permeability and inflammation in vitro in vascular endothelial cells. Transfusion. 2013;53:80S-90.

38. Torres $L N$, Sondeen JL, Ji L, Dubick MA, Filho IT. Evaluation of resuscitation fluids on endothelial glycocalyx, venular blood flow, and coagulation function after hemorrhagic shock in rats. J Trauma Acute Care Surg. 2013;75:759-66.

39. Kozar RA, Peng Z, Zhang R, Holcomb JB, Pati S, Park P, et al. Plasma restoration of endothelial glycocalyx in a rodent model of hemorrhagic shock. Anesth Analg. 2011;112:1289-95.

40. Borgman MA, Spinella PC, Perkins JG, Grathwohl KW, Repine T, Beekley AC, et al. The ratio of blood products transfused affects mortality in patients receiving massive transfusions at a combat support hospital. J Trauma. 2007:63:805-13.

41. Sperry JL, Ochoa JB, Gunn SR, Alarcon LH, Minei JP, Cuschieri J, et al. An FFP:PRBC transfusion ratio $>/=1: 1.5$ is associated with a lower risk of mortality after massive transfusion. J Trauma. 2008;65:986-93.

42. Arinsburg SA, Skerrett DL, Karp JK, Ness PM, Jhang J, Padmanabhan A, et al. Conversion to low transfusion-related acute lung injury (TRALI)-risk plasma significantly reduces TRALI. Transfusion. 2012;52:946-52.

\section{Submit your next manuscript to BioMed Central and take full advantage of:}

- Convenient online submission

- Thorough peer review

- No space constraints or color figure charges

- Immediate publication on acceptance

- Inclusion in PubMed, CAS, Scopus and Google Scholar

- Research which is freely available for redistribution 